Hydrol. Earth Syst. Sci., 15, 1921-1935, 2011

www.hydrol-earth-syst-sci.net/15/1921/2011/

doi:10.5194/hess-15-1921-2011

(C) Author(s) 2011. CC Attribution 3.0 License.

\title{
Data-driven catchment classification: application to the pub problem
}

\author{
M. Di Prinzio, A. Castellarin, and E. Toth \\ DICAM - Department of Civil and Environmental Engineering - University of Bologna, Viale Risorgimento 2, \\ 40136 Bologna, Italy
}

Received: 23 December 2010 - Published in Hydrol. Earth Syst. Sci. Discuss.: 18 January 2011

Revised: 11 May 2011 - Accepted: 6 June 2011 - Published: 23 June 2011

\begin{abstract}
A promising approach to catchment classification makes use of unsupervised neural networks (Self Organising Maps, SOM's), which organise input data through non-linear techniques depending on the intrinsic similarity of the data themselves. Our study considers $\sim 300$ Italian catchments scattered nationwide, for which several descriptors of the streamflow regime and geomorphoclimatic characteristics are available. We compare a reference classification, identified by using indices of the streamflow regime as input to SOM, with four alternative classifications, which were identified on the basis of catchment descriptors that can be derived for ungauged basins. One alternative classification adopts the available catchment descriptors as input to SOM, the remaining classifications are identified by applying SOM to sets of derived variables obtained by applying Principal Component Analysis (PCA) and Canonical Correlation Analysis (CCA) to the available catchment descriptors. The comparison is performed relative to a PUB problem, that is for predicting several streamflow indices in ungauged basins. We perform an extensive cross-validation to quantify nationwide the accuracy of predictions of mean annual runoff, mean annual flood, and flood quantiles associated with given exceedance probabilities. Results of the study indicate that performing PCA and, in particular, CCA on the available set of catchment descriptors before applying SOM significantly improves the effectiveness of SOM classifications by reducing the uncertainty of hydrological predictions in ungauged sites.
\end{abstract}

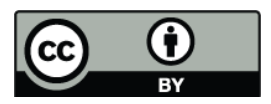

Correspondence to: A. Castellarin (attilio.castellarin@unibo.it)

\section{Introduction}

A common problem in hydrology is the prediction in ungauged basins of the streamflow regime (e.g., long-term mean value and variability of streamflows, flood flows associated with a given exceedance probability, low-flow indices, etc.). The scientific literature has often highlighted the remarkable natural variability of geomorphological characteristics of basins and of their hydrological behavior for different climatic inputs. This consideration motivated the pursuit of general laws in hydrology to be used for predicting the hydrologic behavior of ungauged basins on the basis of historical data.

This issue is eloquently stated by Dooge (1986) in the well known work "Looking for hydrologic laws", but, at the same time, it is also the central topic of many recent international scientific initiatives, such as the Prediction in Ungauged Basins (PUB) of the International Association of Hydrological Sciences (IAHS) (see e.g., Sivapalan et al., 2003). The scientific community states that little progress has been made in this field in the last two decades and indicates that the formulation of objective criteria for catchment classification is one of the main objectives for obtaining a better interpretation and representation of spatiotemporal variability of streamflows (McDonnell and Woods, 2004; McDonnell et al., 2007; Bai et al., 2009).

The identification of hydrologically homogeneous regions, or equivalently the classification of catchments into homogeneous groups having the same hydrologic behaviour, is the basis of all regionalization procedures. These latter are among the most commonly used approaches for predicting streamflow regimes in ungauged basins (Castellarin et al., 2001, 2004; Castellarin, 2007). In particular, catchment classification may support regionalization of rainfall-runoff parameters (Hundecha et al., 2008), a topical issue in hydrology

Published by Copernicus Publications on behalf of the European Geosciences Union. 
(see e.g., Bardossy, 2007; Yadav et al., 2007; Castiglioni et al., 2010), which is also is particularly relevant to the PUBproblem.

A very interesting and promising approach to classification makes use of an innovative and data-driven classification method based on unsupervised artificial neural networks (ANNs), known as Self Organising Maps (SOM, Kohonen, 1982, Toth, 2009; Ley et al., 2011).

As in previous recent studies (Hall and Minns, 1999; Jungy and Hall, 2004; Srinivas et al., 2008), the main goal of our study is to assess whether SOM classifications may be effectively utilized for reducing the uncertainty of hydrological predictions in ungauged basins.

The element of novelty of this study consists in the integration of SOM techniques with two multivariate analysis techniques that reduce the original high-dimensionality of geomorphoclimatic pattern information, namely the Principal Component Analysis (PCA) and Canonical Correlation Analysis (CCA) (see e.g., Krzanowski, 1988; Ouarda et al., 2001). It has been shown for other disciplines that integrating PCA and CCA improves the practical usability of SOM classifications (see Yan et al., 2001). Our study aims at understanding if integrating PCA and CCA with SOM can also be a useful resource in the PUB context.

Our study considers a national database counting 296 Italian unregulated catchments compiled within the national research project "CUBIST - Characterisation of Ungauged Basins by Integrated uSe of hydrological Techniques" (Claps and the Cubist Team, 2008). The streamflow regime and the physiographic and climatic characteristics of the study catchments are summarised by several catchment descriptors. The background idea is the identification of a multipurpose catchment classification that could, in principle, serve different hydrological analyses and be used for addressing different PUB problems (for example design flood estimation or assessment of long-term surface water availability).

We identify a Reference Classification (RC) of the study catchments to be compared with four Alternative Classifications (AC's) in the context of PUB. RC results from the application of SOM to a set of descriptors of the streamflow regime, whereas AC's are identified on the basis of catchment descriptors that are commonly available for ungauged basins. The first AC adopts a set of geomorphoclimatic descriptors as input to SOM. The remaining AC's are identified by applying SOM to three sets of derived variables obtained by applying PCA (second AC) and CCA (third and fourth AC's) to the available geomorphoclimatic descriptors.

First, the similarity between each $\mathrm{AC}$ and $\mathrm{RC}$ is assessed qualitatively, analysing how the study catchments were grouped together. Second, AC's are compared with $\mathrm{RC}$ in terms of accuracy of streamflow prediction. To this aim, AC's and RC are used as basis to regionalise several streamflow indices. In order for the comparison to be fair we adopted the same regionalization approach for all classifications, and we performed an extensive cross-validation procedure to quantify nationwide the accuracy of estimates of the mean annual flow, mean annual flood, and flood quantiles associated with given exceedance probabilities.

\section{Catchment classification and som}

\subsection{Literature review}

A catchment may be defined as the area which drains naturally to a particular point on a river or stream. Catchments are very complex systems, these landscape elements can have different sizes and characteristics. In general it is hard to identify an appropriate classification system that may have general applicability. The recent emphasis on catchment classification highlights the need for methodical criteria to classify catchments and their hydrological behaviour (McDonnell and Woods, 2004). To date, hydrologists have not reached a consensus on a classification system (McDonnell et al., 2007; Wagener et al., 2007).

Regionalization procedures are generally based on the definition of hydrologically homogeneous regions or pooling groups of sites. Regionalization is a commonly used approach for predicting streamflow regimes in ungauged basins (see e.g., Castellarin et al. 2001, 2004; Castellarin, 2007).

The majority of the pioneering studies on catchment classification and hydrological regionalization adopted the geographic contiguity criterion. Nevertheless, very soon the scientific community urged for a globally agreed upon classification system, based on the variability of physical and climatic characteristics of the catchments (Acreman and Sinclair, 1986) and identifiable by means of objective methodologies (i.e., cluster analysis, Burn, 1989).

In recent years a number of techniques based on various mathematical approaches have been proposed by the literature. A very interesting and promising approach to classification makes use of unsupervised artificial neural networks (ANN) (see e.g., Hall and Minns, 1999). Over the last decades ANN's have been subject to an increasing interest in a variety of practical applications. The increasing number of applications of ANN's is related to their ability to relate input and output variables in complex systems without any requirement of a detailed understanding of the physics of the process involved (Dawson and Wilby, 2001). The unsupervised ANN differ from supervised ANN, which are more commonly used in hydrology, because they do not focus on the identification of a relationship between input and output variables. They organize input data through non-linear techniques depending on their similarity instead.

\subsection{SOM networks and catchment classification}

The scientific community shows a growing interest in ANN's application to water resources problems (see e.g., Maier and Dandy, 2000; Maier et al., 2010). Concerning the problems of classification and pattern recognition, Self Organising 
Maps (SOM's, Kohonen, 1982; 1997) are an unsupervised learning method to analyze, cluster, and model various types of large databases. The SOM method counts several hydrological applications (see e.g., Kalteh et al., 2008; Céréghino and Park, 2009), such as classification of hydrological and meteorological conditions for streamflow forecasting (Toth, 2009). SOM networks cluster groups of similar input patterns from a high dimensional input space in a non-linear fashion onto a low dimensional (most commonly two-dimensional for representation and visualization purposes) discrete lattice of neurons in an output layer (Kohonen, 2001; Kalteh et al., 2008).

Typically a SOM consists of two layers, an input layer and a Kohonen or output layer (see Fig. 1 after Kalteh et al., 2008). The input layer contains one neuron for each variable (i.e., catchment attribute) in the data set. The number of classes (i.e., neurons of the output layer) is generally predefined by the modeller and the classes themselves are ordered into meaningful maps that preserve the topology (see Kalteh et al., 2008). The output-layer neurons are connected to every neuron in the input layer through adjustable weights (see Fig. 1), whose values are identified through an iterative training procedure. Lateral interaction between neighbouring output nodes ensures that learning is a topology-preserving process in which the network adapts to respond in different locations of the output layer for inputs that differ, while similar input patterns activate units that are close together. Following a random initialisation of the weight vectors, SOM utilizes a type of learning that is called competitive, unsupervised, or self-organizing procedure to match each input vector with only one neuron in the output layer. This is done by comparing the presented input pattern with each of the SOM neuron weight vectors, on the basis of a distance measure, like the Euclidean distance. The neuron with the closest match to the presented input pattern is called winner neuron. Then, the weight vector of the winner neuron and of the topologically neighbouring neurons are updated in such a way as to reproduce the input pattern (see e.g., Kalteh et al., 2008 and Toth, 2009 for further details).

Once trained (calibrated), the network activates only one output node in correspondence of each input vector. Therefore, all input vectors activating the same node belong to the same class.

\section{Multivariate analysis for dimensionality reduction}

\subsection{Principal Component Analysis - PCA}

The Principal Component Analysis, PCA (see e.g., Krzanowski, 1988), is a multivariate analysis statistical method that enables one to obtain smaller number of uncorrelated variables from a larger number of possibly correlated variables by constructing an orthogonal basis for the original variables themselves. The derived uncorrelated variables

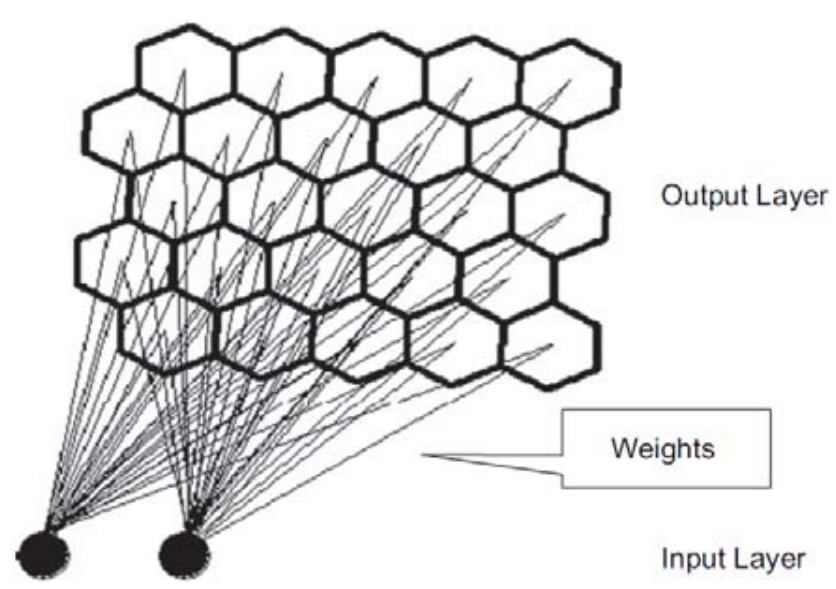

Fig. 1. Structure of a $5 \times 5$ two-dimensional self organizing map (SOM) (after Kalteh et al., 2008).

are called principal components (PC). The full set of PC's has the same dimensionality of the original set of variables. They are ordered in such a way that the first component accounts for as much of the variability in the original dataset as possible, and each following PC accounts for as much of the remaining variability as possible.

It is commonplace for the sum of the variances of the first few PCs to exceed $80 \%$ of the total variance of the original data. By examining plots of these few new variables, researchers often develop a deeper understanding of the driving forces that generated the original data. The literature reports several criteria for selecting the appropriate number of principal components (see e.g. Kaiser, 1960 criterion and the scree plot).

\subsection{Canonical Correlation Analysis - CCA}

Another important multivariate statistical tool for reducing the dimensionality of the original dataset is the Canonical Correlation Analysis (CCA). The multivariate approach of CCA is most commonly used in the context where there are two sets of random multidimensional and correlated variables $\boldsymbol{X}=\left\{X_{1}, X_{2}, \ldots, X_{n}\right\}$ and $\boldsymbol{Y}=\left\{Y_{1}, Y_{2}, \ldots, Y_{m}\right\}$ (e.g., geomorphoclimatic catchment descriptors and indices of the streamflow regime, such as the annual flow, the flood associated with a given recurrence interval, etc.). CCA enables one to identify the dominant linear modes of covariability between the sets $\boldsymbol{X}$ and $\boldsymbol{Y}$ (see e.g., Krzanowski, 1988; Ouarda et al., 2001). In other words, CCA identifies two new groups of artificial variables (canonical variables) $\boldsymbol{U}=\left\{U_{1}, U_{2}, \ldots, U_{r}\right\}$ and $\boldsymbol{V}=\left\{V_{1}, V_{2}, \ldots, V_{r}\right\}$, with $r=\min \{n, m\}$, by finding linear combinations of the original $X_{i}$, with $i=1, \ldots, n$, and $Y_{j}$, with $j=1, \ldots, m$, in such a way that the correlation between the canonical variables of a pair $\left(U_{i}, V_{i}\right)$ is maximized and the correlation between the variables of different pairs is null (Chokmani and Ouarda, 2004; Shu and Ouarda, 2007). 
Table 1. Minimum, mean and maximum values, and 25th, 50th and 75th percentiles for the set of $X$ variables considered in the study. These data were either derived from a SAR-DTM (Synthetic Aperture Radar - Digital Terrain Model) with grid size $100 \mathrm{~m}$ or $*$ retrieved from Rep. no 17 of the former Italian SIMN (National Hydrographic Service of Italy).

\begin{tabular}{lrrrrrrrrrrrr}
\hline & $\begin{array}{r}\text { long. } \\
(\mathrm{m})\end{array}$ & $\begin{array}{r}\text { lat. } \\
(\mathrm{m})\end{array}$ & $\begin{array}{r}A \\
\left(\mathrm{~km}^{2}\right)\end{array}$ & $\begin{array}{r}P \\
(\mathrm{~km})\end{array}$ & $z_{\max }$ & $\begin{array}{r}z_{\min } \\
(\mathrm{m} \text { a.s.1.) }\end{array}$ & $z_{\text {mean }}$ & $\begin{array}{r}L \\
(\mathrm{~km})\end{array}$ & $\begin{array}{r}S_{\mathrm{L}} \\
(\%)\end{array}$ & $\begin{array}{r}S_{\mathrm{A}} \\
(\%)\end{array}$ & $\begin{array}{r}\Phi \\
(\mathrm{deg} . \mathrm{N} .)\end{array}$ & $\begin{array}{r}\text { MAP* } \\
(\mathrm{mm})\end{array}$ \\
\hline Minimum & 319450 & 4170550 & 3.2 & 8.0 & 284 & 3.0 & 127.0 & 2.6 & 1.8 & 6.2 & 0.7 & 602.0 \\
Mean & 704261 & 4752661 & 1060.8 & 157.8 & 2092 & 342.0 & 986.7 & 54.8 & 10.1 & 29.1 & 186.6 & 1224.2 \\
Maximum & 1162850 & 5195450 & 17512.1 & 1115.0 & 4727 & 1812.0 & 3110.0 & 357.9 & 35.4 & 63.0 & 359.3 & 2289.0 \\
25th & 505825 & 4545450 & 98.0 & 52.75 & 1409 & 77.7 & 567.5 & 18.7 & 5.3 & 18.4 & 73.9 & 960.75 \\
50th & 680450 & 4814250 & 331.0 & 102.5 & 1814 & 231.5 & 838.5 & 35.9 & 8.5 & 26.8 & 204.0 & 1152.5 \\
75th & 897475 & 4922150 & 930.7 & 187.25 & 2625 & 462.5 & 1242.7 & 66.1 & 13.6 & 38.5 & 276.8 & 1410.0 \\
\hline
\end{tabular}

If we denote by $\boldsymbol{X}$ and $\boldsymbol{Y}$ the independent and dependent variables respectively and we consider the linear transformations,

$$
\boldsymbol{U}=\boldsymbol{u}_{\boldsymbol{X}}^{\mathrm{T}} \cdot \boldsymbol{X} \text { and } \boldsymbol{V}=\boldsymbol{u}_{\boldsymbol{Y}}^{\mathrm{T}} \cdot \boldsymbol{Y}
$$

characterized by the basis vectors $\boldsymbol{u}_{\boldsymbol{X}}$ and $\boldsymbol{u}_{\boldsymbol{Y}}$, CCA can be defined as the following optimization problem,

$$
\rho=\max _{\boldsymbol{u}_{\boldsymbol{X}}, \boldsymbol{v}_{\boldsymbol{Y}}}\{\operatorname{corr}(\boldsymbol{U}, \boldsymbol{V})\}=\max _{\boldsymbol{u}_{\boldsymbol{X}}, \boldsymbol{v}_{\boldsymbol{Y}}} \frac{\operatorname{cov}(\boldsymbol{U}, \boldsymbol{V})}{\sqrt{\operatorname{var}(\boldsymbol{U})} \sqrt{\operatorname{var}(\boldsymbol{V})}} .
$$

\section{Study area and available information}

The study area consists of 296 Italian catchments scattered nationwide, whose dataset was compiled within the national research project "CUBIST - Characterisation of Ungauged Basins by Integrated uSe of hydrological Techniques" (see e.g., Claps et al., 2008), and is definitely heterogeneous in terms of climatic and geomorphologic characteristics that control the streamflow regime.

\subsection{Geomorphoclimatic and streamflow variables}

We refer to 12 different geomorphological and climatic descriptors of the study catchments, which we term in the study $X$ variables, and 6 descriptors of the streamflow regime, which we term $Y$ variables.

$X$ variables:

- (1 and 2) long. and lat. - UTM longitude and latitude of catchment centroid;

- (3) A - Drainage area;

- (4) P - Perimeter;

- (6) $z_{\max }-$ Highest elevation;

- (6) $z_{\min }$ - Elevation of the catchment outlet;

- (7) $z_{\text {mean }}$ - Mean altitude;

- (8) L - Maximum drainage length;
- (9) $S_{\mathrm{L}}$ - Average slope along the maximum drainage length;

- (10) $S_{\mathrm{A}}$ - Catchment average slope;

- (11) $\Phi-$ Catchment orientation;

- (12) MAP - Mean Annual Precipitation;

$Y$ variables:

- (1) MAR - Mean Annual Runoff;

- (from 2 to 5 ) $l_{i}$ - sample $\mathrm{L}$ moments of order $i=1$ (i.e., sample mean), 2, 3 and 4 of the annual maximum series AMS of flood flows (see e.g., Hosking, 1990);

- (6) REC/l 1 - Ratio between the maximum value and the sample mean of AMS of flood flows.

Tables 1 and 2 summarise $X$ and $Y$ variables in terms of minimum, mean and maximum values, and 25th, 50th and 75 th percentiles for the set of 296 considered catchments.

Concerning the $X$ variables, it is worth remarking that we did not make any a-priori assumption to form the dataset of physiographic and climatic descriptors, since we were already constrained by the intrinsic difficulty of compiling a homogeneous and consistent National dataset for $~ 300$ catchments. We included as many relevant catchment descriptors as possible, using multivariate analysis techniques (i.e., PCA and CCA) to sort out noise and redundancy (Chokmani and Ouarda, 2004; Castiglioni et al., 2011) while retaining the information that is the most descriptive of the streamflow regime (see e.g., Krzanowski, 1988; Ouarda et al., 2001). Concerning $Y$ and $X$ variables, we acknowledge that our dataset lacks information concerning base-flow, subsurface characteristics, land-cover and vegetation, which are extremely relevant to the catchment-classification problem, but unfortunately we could not find consistent and homogeneous information on these characteristics nationwide. 


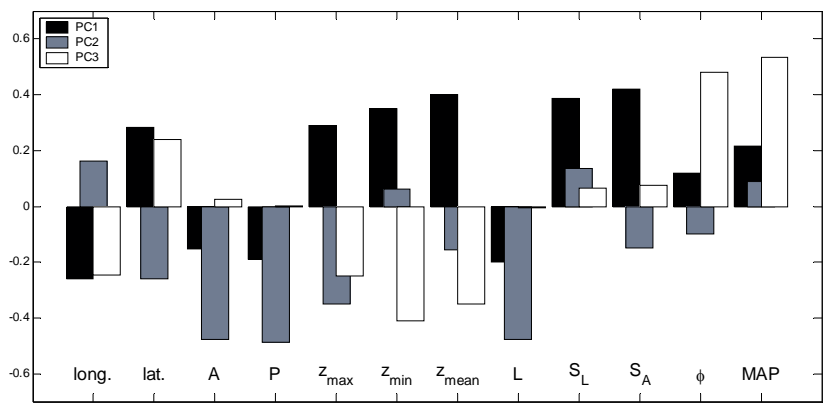

Fig. 2. Coefficients of the linear transformation for the first three PC's of the $X$ variables.

\subsection{Application of PCA and CCA}

We reduced the dimensionality of the 12-dimensional space of the geomorphoclimatic descriptors ( $X$ variables) and the 6-dimensional space of the streamflow regime descriptors $(Y$ variables) through the application of PCA and CCA. In particular we computed all PC's of $X$ variables relative to the whole set of 296 basins. As said before, the full set of PC's is as large as the original set of variables. The 12 PC's have zero mean and a decreasing standard deviation (see Table 3), but the most interesting property is that the first three principal components explain roughly the two third of the total variability, in this case more than the $75.4 \%$ (Table 3).

Figure 2 reports the coefficients of linear transformation of each $X$ variable for the first three Principal Components. This information is explained from the eigenvalues calculated for our dataset.

Likewise, we applied the CCA to the set of $X$ and $Y$ variables relative to the whole of the 296 study basins. As reported above, the number of canonical variables is equal to the smallest dimension of the two sets of variables, in our case the $Y$ variables. Therefore we obtained 6 canonical variables for each set, $\mathbf{U}$ and $\mathbf{V}$.

The scatter-plots of Fig. 3 illustrate the relationships between the canonical variables $\mathbf{U}$ (x-axis) and $\mathbf{V}$ (y-axis) computed for the study area, also illustrating, as expected, a significant correlation between the first canonical variables $U_{i}$ and $V_{i}$. Table 4 shows the significance of the null hypothesis that all correlation coefficients between $U_{j}$ and $V_{j}$ - with $j=i, \ldots r=6-$ are zero. As Table 4 shows, the first 4 canonical variables are the most descriptive for the problem at hand. As done for PC's, we report in Fig. 4 the coefficients of linear transformation associated with each $X$ variable for all six components of $\mathbf{U}$.

\section{Comparison of som classifications of the study catchments}

There are no predefined classes of the conditions characterising the basin: a clustering algorithm is here used as an

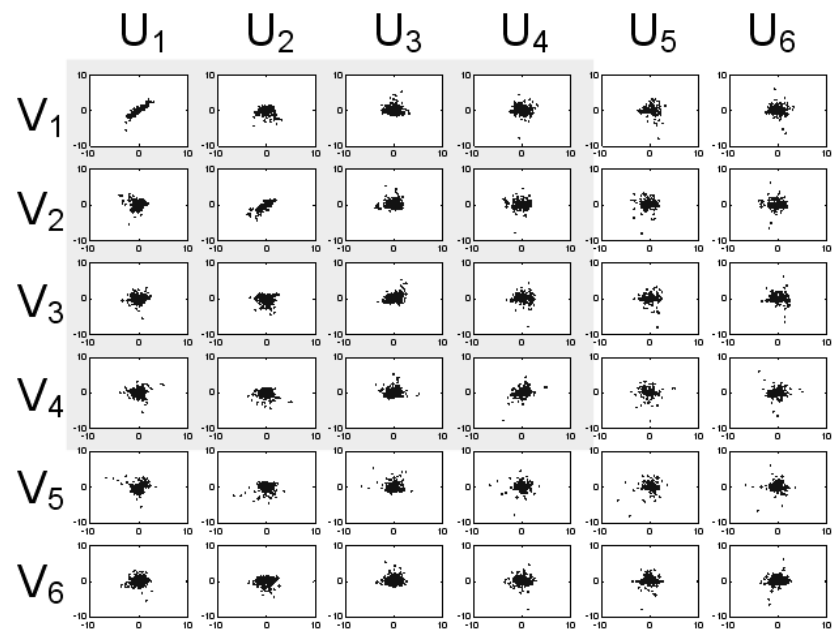

Fig. 3. Canonical variables $\mathbf{U}$ and $\mathbf{V}$ computed for the study area: scatter-plots between canonical variables $U_{i}$ and $V_{j}$, for $i$ and $j$ equal to $1,2, \ldots 6$.

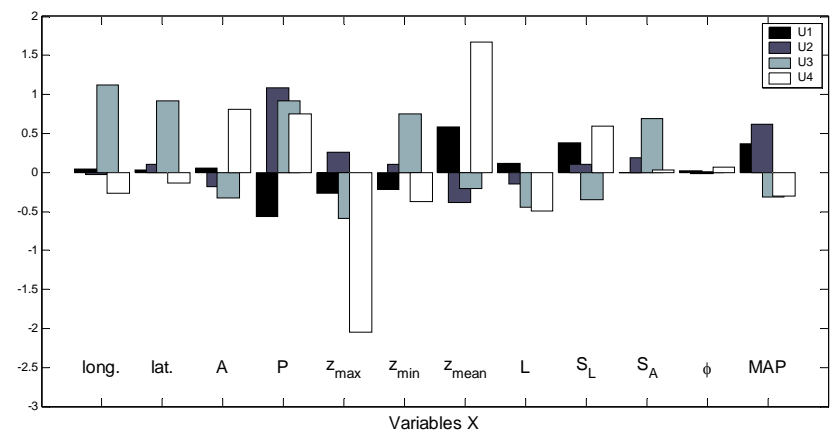

Fig. 4. Coefficients of the linear transformation for the canonical variables of the $X$ variables.

unsupervised classifier, where the task is to learn a classification from the data. Such partitioning will be based on the most relevant available information, that is, descriptors of the streamflow regime and geomorphoclimatic characteristics. Our study identifies several classifications on the basis of different sets of catchment descriptors (Sect. 5.1) by implementing different SOM networks (Sect 5.2); we then compare these classifications by looking at the similarity of the partitions (Sect. 5.3) and by assessing the performance of each classification for the prediction of streamflow indices in ungauged basins (Sect. 5.4).

\subsection{Reference and alternative SOM classifications}

We considered 5 different SOM classifications: a reference SOM classification and 4 alternative SOM classifications. These classifications were obtained for the considered group of catchments on the basis of the information described below: 
Table 2. Minimum, mean and maximum values, and 25th, 50th and 75th percentiles for the set of $Y$ variables considered in the study. These data were either computed from the digital database of Italian AMS of flood flows compiled during the Italian VaPi (GNDCI-CNR) project or * retrieved from Rep. no 17 of the former Italian SIMN (National Hydrographic Service of Italy).

\begin{tabular}{lrrrrrr}
\hline & $\begin{array}{r}\text { MAR* } \\
(\mathrm{mm})_{-}\end{array}$ & $\begin{array}{r}\mathrm{l}_{1} \\
\left(\mathrm{~m}^{3} \mathrm{~s}^{-1}\right)_{-}\end{array}$ & $\begin{array}{r}\mathrm{l}_{2} \\
\left(\mathrm{~m}^{3} \mathrm{~s}^{-1}\right)_{-}\end{array}$ & $\begin{array}{r}\mathrm{l}_{3} \\
\left(\mathrm{~m}^{3} \mathrm{~s}^{-1}\right)_{-}\end{array}$ & $\begin{array}{r}\mathrm{l}_{4} \\
\left(\mathrm{~m}^{3} \mathrm{~s}^{-1}\right)_{-}\end{array}$ & $\begin{array}{r}\mathrm{REC} / \mathrm{l}_{1} \\
(-)\end{array}$ \\
\hline Minimum & 84.0 & 1.0 & 0.3 & -27.3 & -32.3 & 1.2 \\
Mean & 780.6 & 309.0 & 86.1 & 21.0 & 16.5 & 2.7 \\
Maximum & 4406.0 & 1881.6 & 584.8 & 154.6 & 222.1 & 9.5 \\
25th & 384.7 & 56.1 & 17.8 & 2.6 & 2.3 & 1.9 \\
50th & 653 & 163.0 & 51.7 & 12.1 & 9.5 & 2.5 \\
75th & 1080.2 & 418.0 & 123.6 & 29.3 & 21.7 & 3.3 \\
\hline
\end{tabular}

Table 3. Principal Components of $X$ variables: variability accounted for.

\begin{tabular}{lrrr}
\hline & $\begin{array}{r}\text { Standard } \\
\text { Deviation } \\
(-)\end{array}$ & $\begin{array}{r}\text { Proportion } \\
\text { of Variance } \\
(\%)\end{array}$ & $\begin{array}{r}\text { Cumulative } \\
\text { Proportion } \\
(\%)\end{array}$ \\
\hline PC1 & $\mathbf{2 . 1 1}$ & $\mathbf{3 7 . 0 0}$ & $\mathbf{3 7 . 0 0}$ \\
PC2 & $\mathbf{1 . 8 4}$ & $\mathbf{2 8 . 2 0}$ & $\mathbf{6 5 . 2 0}$ \\
PC3 & $\mathbf{1 . 1 1}$ & $\mathbf{1 0 . 2 0}$ & $\mathbf{7 5 . 4 0}$ \\
PC4 & 0.97 & 7.90 & 83.30 \\
PC5 & 0.89 & 6.53 & 89.83 \\
PC6 & 0.67 & 3.69 & 93.52 \\
PC7 & 0.60 & 3.02 & 96.54 \\
PC8 & 0.49 & 1.98 & 98.52 \\
PC9 & 0.28 & 0.64 & 99.16 \\
PC10 & 0.25 & 0.54 & 99.70 \\
PC11 & 0.15 & 0.19 & 99.88 \\
PC12 & 0.12 & 0.12 & 100.00 \\
\hline
\end{tabular}

- Reference Classification (RC)

- SOMY is obtained by using indices of the streamflow regime ( $Y$ variables);

- Alternative Classifications (ACs):

- SOMX is based upon the geomorphoclimatic descriptors ( $X$ variables);

- SOMPC3 uses the first three Principal Components of the $X$ variables;

- SOMU uses all canonical variables computed by applying CCA to $X$ and $Y$ variables (i.e., $U_{i}$, with $i=1, \ldots, 6)$;

- SOMU4 uses a subset containing the most descriptive canonical variables (i.e., $U_{i}$, with $i=1, \ldots, 4$ ).

\subsection{SOM classification implementation}

A different SOM network was implemented for each set of catchment characteristics (Y, X, U, U4, PC3). The dimension
Table 4. Canonical Correlation Analysis: level of significance $\alpha$ of the null-hypothesis that the $i^{\text {th }}$ through the $6^{\text {th }}$ correlations are all zero.

\begin{tabular}{ccc}
\hline$i$ & $\rho\left(U_{i}, V_{i}\right)$ & Significance $\alpha$ \\
\hline 1 & 0.900 & 0.00 \\
2 & 0.830 & 0.00 \\
3 & 0.498 & 0.00 \\
4 & 0.362 & 0.00 \\
5 & 0.244 & 0.06 \\
6 & 0.165 & 0.34 \\
\hline
\end{tabular}

of the input layer varies from 3 (PC3) to 12 (X). As far as the output layer is concerned, there is not a predefined number of classes and it was here chosen an hexagonal topology formed by three rows by three columns, for a total of nine nodes, each one corresponding to a class.

It is worth remarking here that the selection of the metric, network topology and number of classes, are, to some extent, subjective choices that may influence the application of the SOM method. For this reason it is always advisable to run exploratory analyses to guide the implementation of the SOM network, and the selection of the most appropriate scheme for the problem at hand. Preliminary analyses (see Toth and Castellarin, 2008) revealed that nine classes is a good compromise between homogeneity and size of each class for classes identified on the basis of the physiographic and climatic descriptors (i.e., $X$ variables), where homogeneity has to be interpreted in terms of variability of physiographic and climatic catchment descriptors. Therefore, nine was selected as the number of classes for all classifications in order for the comparison to be consistent. Some classifications are based on a much smaller number of descriptors (e.g. three for SOMPC3). Even though the first three principal components account for a large portion of the variability in the original set of descriptors through linear combinations, it has to be remembered that SOM's are formed through a non-linear and unsupervised process. We therefore believe that a larger number of classes may be adequate also in this 


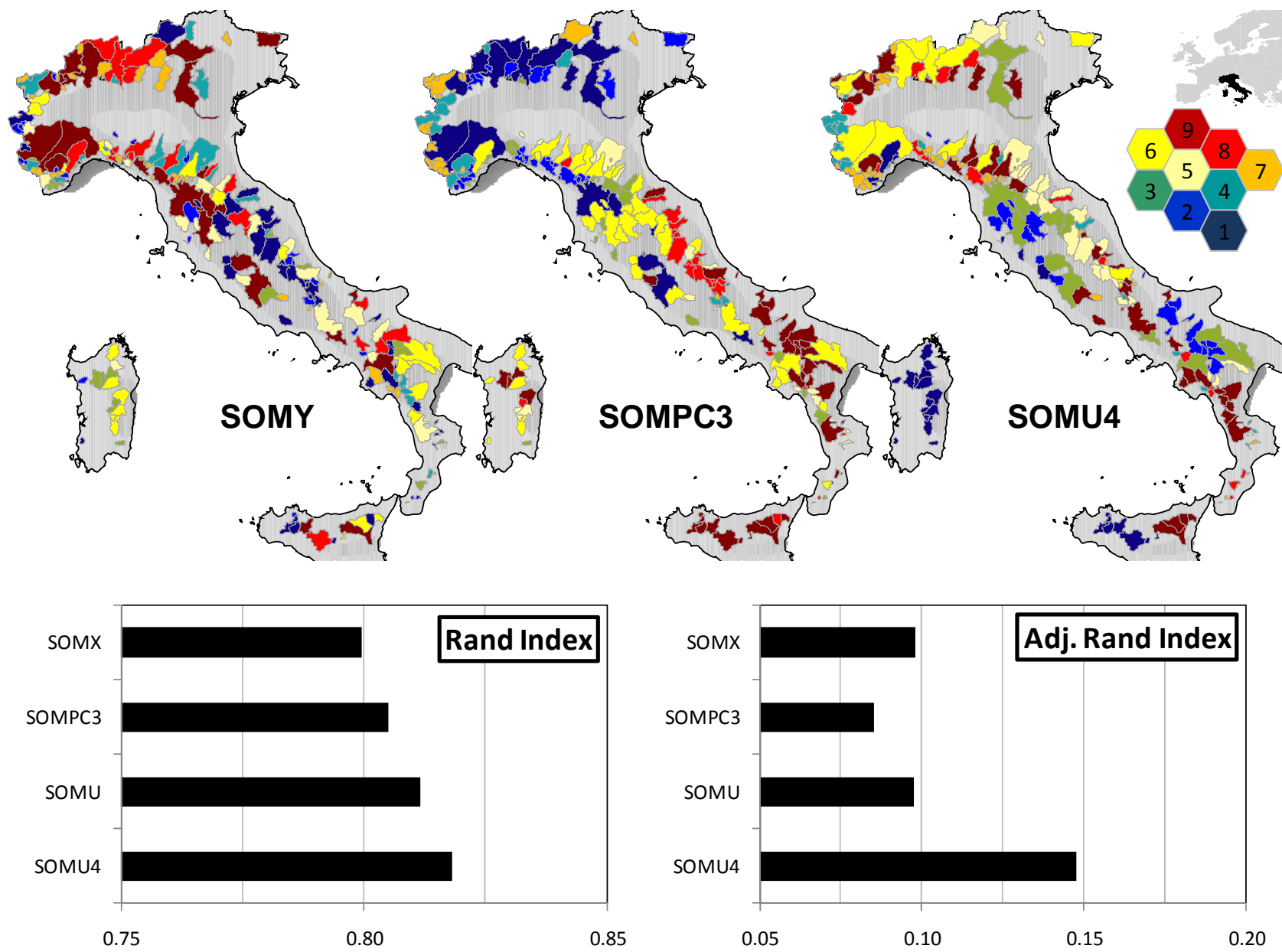

Fig. 5. SOM classifications of the study catchments (note that SOMU is omitted) and hexagonal topology of the output layer; bar-diagram for Rand and Adjusted Rand Index.

case and deemed nine classes suitable for all classifications (i.e., the one based upon $6 Y$ variables, and those based upon $12 X$ variables and their linear combinations). We used the Euclidean distance as a measure of the distance between the vectors, according to the majority of hydrological applications.

Three out of five SOM's classifications resulting from the different sets of descriptors are represented in Fig. 5 (SOMX and SOMU were omitted due to space limitations). Note that no relationship exists between classes depicted by the same colour in different classifications.

The three different SOM's classifications resulted in visibly different grouping of the catchments, but also a high level of consistency exists across the three maps, suggesting that groups of landscape-climate similarity are largely independent of the method of classification used.

A detailed and comprehensive physically based interpretation of the patterns emerging from the different classifications is clearly out of the scope of our analysis, which assesses whether (unsupervised and objective) multivariate techniques may improve the effectiveness of an unsupervised and objective approach (Self Organizing Maps, SOM's) to the problem of catchment classification within the general PUB context. Nevertheless, we believe that a brief discussion of the reference classification, SOMY, may be of interest and use for a number of reasons and, in particular, for assessing the value of the $\mathrm{RC}$ itself from a hydrological perspective. Figure 6 presents SOMY by mapping each cluster separately onto the 9-node output layer, on which, as mentioned above, similar clusters are close together, whereas different clusters are far from each other. Concerning catchment size and referring to it in relative terms in respect of the study area, class 9 groups mainly large catchments, medium catchments are largely grouped in classes 1, 4, 5, 6 and 8, while small catchment belong mainly to classes 2,3 and 7 . Class 7 is far from 2 and 3 and it may be noted that, while class 7 groups many small Alpine catchments (high altitudes, continental climate), classes 2 and 3, which are close together include mainly small Apenninic and medium inland Sardinian catchments. Concerning medium catchments, it 


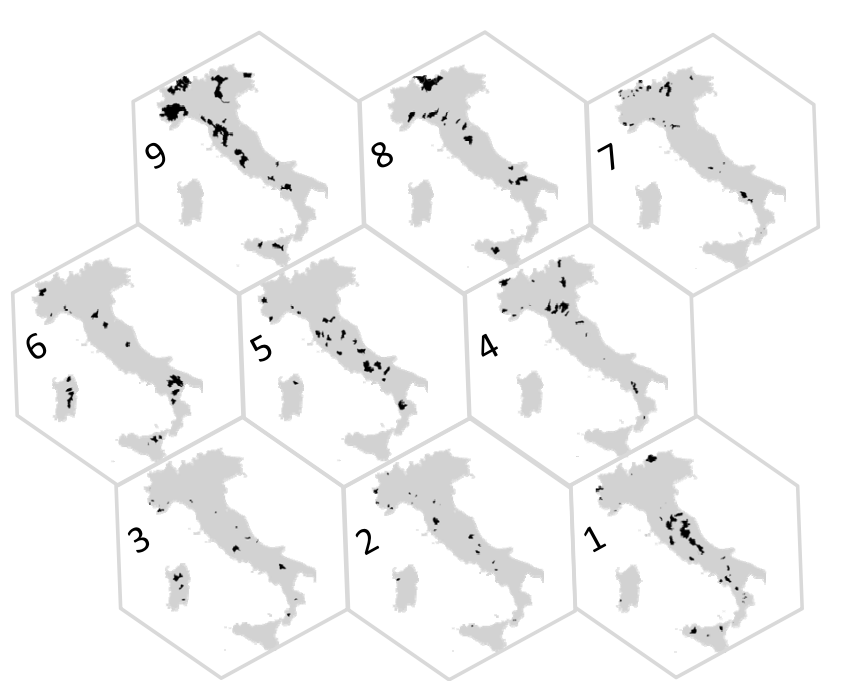

Fig. 6. Reference classification SOMY.

may be noted that classes $8,6,5,4$ and 1 can be associated with very clear patterns: class 8 is mainly representative of Northern catchments that, particularly for the Apenninic ones show a high degree of homogeneity in the flood frequency regime (see e.g., Castellarin et al., 2001; Castellarin, 2007); catchments belonging to class 6 are predominantly characterized by a maritime regime, the class groups together insular coastal catchments of Sardinia and Sicily, and Ionian catchments; class 5 includes mainly Apenninic medium catchments characterized by relatively low altitudes; class 4 clusters low-permeability Apenninic catchments (see e.g., Castellarin et al., 2001, 2004); the majority of class 1 catchments are located in areas characterized by limestones and sandstones, often fractured, and, for the limestone areas the presence of karst phenomena (ISPRA-DDS, 2004; Castellarin et al., 2004). Incidentally, it is worth noting that the fact that SOMU4 groups together all Sardinian catchments is a consequence of the rather significant weight longitude and latitude have in the first four canonical variates (see Fig. 4).

Figure 7 compares the SOM classifications in terms of number of basins belonging to each class. The figure reports the sample cumulative distribution functions of the number of basins belonging to the nine classes of each classification, indicating the typical size of each class (average number of basins is equal to 33), together with the variability around the average value. All classifications present similar distributions, even though AC's clearly show a higher degree of similarity among themselves in terms of number of basins in each class. Concerning this point it is worth noting that while $\mathrm{RC}$ is identified on the basis of indices characterizing the streamflow regime, all AC's are delineated by applying SOM techniques to information that can be retrieved for ungauged basins.

Any ungauged basin, once characterized in terms of the 12 considered catchment descriptors, can be allocated to one of

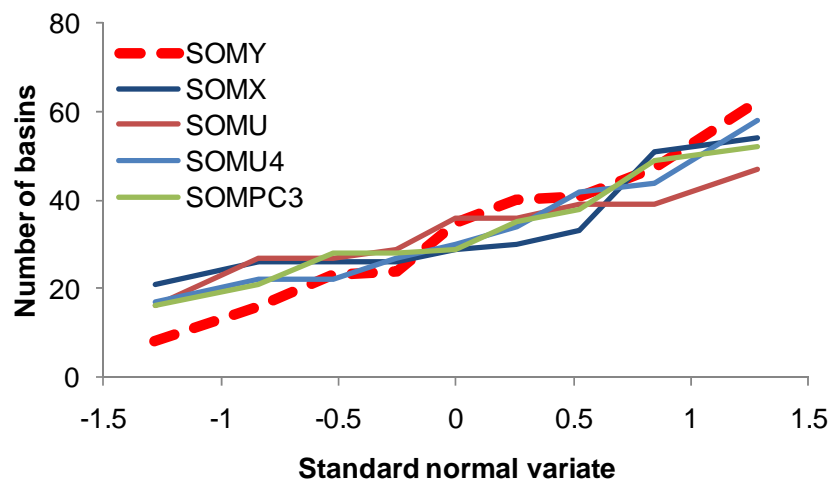

Fig. 7. Sample cumulative distribution function of the number of basins in each class.

the nine classes of each alternative SOM classifications. The regional streamflow information collected within the class to which the ungauged site belongs can then be used to infer the streamflow regime of the ungauged site itself. The next two sections assess the effectiveness of AC's in terms of (1) affinity to the RC and (2) usability in the PUB context to predict the streamflow regime in ungauged catchment.

\subsection{Affinities of alternative SOM classifications with the reference classification}

Two indices of similarity were applied to quantify the affinities between reference (SOMY) and alternative classifications: the Rand Index (Rand, 1971), RI, and its variation proposed by Hubert and Arabie (1985).

Comparing two partitions $\left(P_{1}\right.$ and $\left.P_{2}\right)$ of the same data set, a couple of objects (i.e., catchments) can belong to the same class or different classes in $P_{1}$ and $P_{2}$. Let us define $N_{00}$ as the number of catchments that belong to the same class both in $P_{1}$ and $P_{2} ; N_{10}$ as the number of catchments that belong to the same class in $P_{2}$ but not in $P_{1} ; N_{01}$ as the number of catchments that belong to the same class in $P_{1}$ but not in $P_{2} ; N_{11}$ as the number of catchments that belong to different classes both in $P_{1}$ and $P_{2}$. Under these assumptions, $\mathrm{RI}$ reads,

$\mathrm{RI}=\frac{N_{11}+N_{00}}{N_{11}+N_{00}+N_{10}+N_{01}}$

RI varies between 1 (perfect agreement between the two partitions) and 0 (no agreement).

Hubert and Arabie (1985) proposed an adjustment to the Rand Index so that its expected value is equal to zero for random partitions having the same number of objects in each class. The index is still equal to 1 for perfect agreement but it can also take negative values (higher discriminatory power than RI).

The original Rand Index is sensitive to the number of classes in the partitions, and may be significantly impacted (i.e., one obtains low index values) when the considered 
alternative classification differs from the reference one in terms of number of classes. Also for this reason, we preferred to consider the same number of nodes (i.e., nine) for all SOM classifications to facilitate the comparison.

The bar-diagrams of Fig. 5 show the values obtained for these indices by comparing the RC (i.e., SOMY) with all AC's (i.e., SOMX, SOMPC3, SOMU and SOMU4). RC is based on the use of hydrometric information, therefore the effectiveness of all AC's, which are suitable for ungauged basins, is "measured" relative to SOMY.

Figure 5 shows that, as it was expected, SOMX and SOMPC3 are similar to each other in terms of affinity with SOMY. Figure 5 also shows that SOMU and SOMU4 are more similar to SOMY than SOMX and SOMPC3, indicating that SOMU4 outperforms all other classifications in terms of affinity with the reference classification SOMY.

These results are a consequence of the intrinsic nature of the alternative SOM classifications considered in our study. SOMX uses all geomorphological and climatic descriptors, therefore there is no direct relationship with the information used for delineating SOMY and, also, the information utilised to delineate SOMX presents redundancy that may impact the efficiency of the classification process. SOMPC3 uses only the most descriptive portion of the available geomorphologic and climatic information, therefore removing some noise from the input data, yet there is no direct relation with the hydrometric information also in this case. SOMU, instead, uses as input information geomorphologic and climatic information rearranged to maximize the correlation with the streamflow regime, and SOMU4 uses only the geomorphologic and climatic information which shows the highest correlation with the streamflow regime.

\subsection{Quantitative comparison of SOM classifications in the PUB context}

The effectiveness of each classification has been further assessed relative to the estimation of streamflow regime for ungauged sites. To this aim we developed a number of multiple regression models for estimating the streamflow index of interest in ungauged sites and we assessed the performances of these models in cross-validation for all AC's considered in the study, to better understand whether or not the utilization of PCA and CCA may improve the practical usability of SOM catchment classifications, reducing the uncertainty of predictions in ungauged sites.

For the sake of generality and simplicity, we referred in the study to the simplest possible model structure, therefore adopting a linear multiregression model as the reference model. The model reads,

$\hat{y}_{i}=A_{0}+A_{1} \mathrm{PC}_{i}+A_{2} \mathrm{PC} 2_{i}+A_{3} \mathrm{PC} 3_{i}+\vartheta$

where $A_{0}, A_{1}, A_{2}$ and $A_{3}$ are the parameters of the multivariate linear regression model; $\mathrm{PC} 1_{i}, \mathrm{PC} 2_{i}$ and $\mathrm{PC} 3_{i}$ are the first three principal components of variables $X$ for site $i$, with $i=1, \ldots, 296$, which explain more than the $75.4 \%$ of the total variance and, for consistency, are used as explanatory variables in all multiregression models developed in the study; $\vartheta$ is the residual of the model; and $\hat{y}_{i}$ is the normalized streamflow index of interest for site $i$,

$\hat{y}_{i}=\frac{\hat{z}_{i}-\bar{z}}{s_{Z}}$,

with $\hat{z}_{i}$ empirical value of the streamflow index for site $i$, and $\bar{z}$ and $s_{Z}$ empirical mean and standard deviation of the streamflow index of interest for the entire dataset.

We performed this analysis by developing for each catchment classification of interest four different multiregression models (4), namely one model for estimating of Mean Annual Runoff (MAR) and three models for estimating the first 3 sample $\mathrm{L}$ moments of the annual maximum series $l_{1}, l_{2}$ and $l_{3}$. In particular, four models were identified for RC (i.e., SOMY), which represents the optimal classification, and for each of the four AC's (i.e., SOMX, SOMPC3, SOMU and SOMU4). Four multiple linear regression models were also identified for the entire national set of basins (NOCLASS), which represents a baseline condition in the comparison and sets the minimum level of performance.

We assessed the efficiency of each alternative classification AC by referring to the results of an extensive jack-knife cross-validation of all 24 regression models developed for the six identified classifications (i.e., RC -optimal-, AC's, NOCLASS -baseline-).

The jack-knife cross-validation procedure is applied in order to quantify the accuracy of each model when applied in ungauged basins; it is also called in the literature as deleteone or leave-one-out cross-validation procedure (see e.g., Efron, 1982; Zhang and Kroll, 2007; Brath et al., 2003; Castellarin et al., 2004). This method is extremely versatile and capable of providing adequate evaluation of the performance of the interpolation techniques, since it simulates the ungauged conditions for each site in the study region. The procedure can be illustrated as follows,

1. one catchment is eliminated from the set of $N$ catchments;

2. an empirical multiregression model is identified on the basis of the information collected at the $N-1$ remaining catchments (i.e., the first three principal components are computed and the coefficients $A_{j}$ of (4), with $j=$ $0, \ldots, 3$, are estimated through linear multiregression techniques);

3. the model developed at step (2) is used for estimating the streamflow index at the discarded site;

4. steps (1) to (3) are repeated $N-1$ times, each time by eliminating a different catchment.

In a few words, the jack-knife procedure estimates the streamflow index at stake in a given site without taking into 
account the hydrometric information available at the site itself.

The results of the various cross-validations were quantified in terms of Nash-Sutcliffe efficiency measure (NSE) (Nash and Sutcliffe, 1970). NSE varies in the range ]- $\infty$, 1], where 1 corresponds to a perfect agreement between modelled and empirical values, $\mathrm{NSE}=0$ indicates that estimated values are as accurate as the mean of the observed values, while negative values occur when the observed mean value is a better predictor than the model. The performance index reads

$$
\mathrm{NSE}=1-\frac{\sum_{i=1, N}\left(\eta_{J K, i}-\eta_{i}\right)^{2}}{\sum_{i=1, N}\left(\eta_{i}-\sum_{i=1, N}\left(\frac{\eta_{i}}{N}\right)\right)^{2}}
$$

where $\eta_{J K, i}$ indicates the jack-knife estimate and $\eta_{i}$ the empirical value for site $i$, with $i=1, \ldots, N$.

We computed the performance index relative to jack-knife and empirical values of MAR (Mean Annual Runoff) and $l_{1}$ (mean annual flood). Producing reliable predictions of MAR and $l_{1}$ in ungauged sites is of primary concern (see e.g., Brath et al., 2001; Castellarin et al., 2004; Kjeldsen and Jones, 2010). Concerning the higher order L moments (i.e., $l_{2}$ and $l_{3}$ ), instead of comparing directly empirical and jackknife values we preferred to focus on flood quantiles (i.e., flood flows associated with a given recurrence interval $T$ ), computed on the basis of the L-moments. We deem the flood quantiles to be more meaningful and understandable than $l_{2}$ and $l_{3}$ for summarising the flood frequency regime from a practical viewpoint. Ultimately, hydrologists and practitioners are interested in the estimation of the design flood in ungauged sites rather than the L moments' values.

We estimated the flood quantiles at each and every site from a Generalized Extreme-Value (GEV) distribution estimated with the L moments method (GEV-LMOM algorithm), which is often more efficient than the maximum likelihood when used with small to moderate length samples (please refer to Hosking and Wallis, 1997 for details of the frequency distribution and the method of $\mathrm{L}$ moments). The GEV distribution was selected in light of its satisfactorily reproduction of the sample frequency distribution of hydrological extremes in Italy and around the world (see e.g., Stedinger et al., 1993; Robson and Reed, 1999; Castellarin et al., 2001).

We arbitrarily selected three different return periods, $T=10,50$ and 100 years and we estimated the flood quantiles through the GEV-LMOM algorithm by referring to the sample L moments $l_{1}, l_{2}$ and $l_{3}$ and their jack-knife estimates for all classifications of interest (RC, AC's, NOCLASS). We then compared these estimates in terms of (6). To avoid unduly extrapolations, we limited the comparison for $T=10$ and $50 \mathrm{yr}$ to the 92 out of 296 sites with at least $30 \mathrm{yr}$ of observed annual maxima, and to the 34 out of 296 sites with at least $40 \mathrm{yr}$ of observations for $T=50$ and $100 \mathrm{yr}$.
It is worth highlighting here that even though the use of NSE has become a natural part of the modelling practice, its utilization is still a matter of concern (see e.g., Gupta et al., 2009). In fact, the usefulness of the observed mean as a reference value varies strongly in practical applications. Like all the squared measures, NSE weights the largest observation very heavily at the expense of smaller values, to overcome this problem we computed NSE on logflows, this is typically considered valuable for flood and mean annual streamflows.

\section{Results and discussion}

Table 5 reports the values obtained for NSE for all crossvalidated streamflow indices and classifications. The scatter plots of Fig. 8 report sample estimates of streamflow indices of interest against predicted values obtained in crossvalidation for some of the classifications considered in the study. Distribution of relative residuals between empirical and jack-knifed values of the streamflow index of interest are illustrated in Fig. 9 for NOCLASS, SOMY, SOMPC3 and SOMU.

The comparison between the results obtained for the baseline condition (NOCLASS) and alternative classifications (i.e., SOMX, SOMPC3, SOMU, SOMU4) indicates that all SOM classifications led to a remarkable improvement in the prediction ability of the considered multiregressive model for all streamflow indices considered in the study. NSE values show significant improvements for all streamflow indices and alternative classifications relative to NOCLASS (see Table 5). Also, the comparison between the results obtained for SOMX and those relative to SOMPC3, SOMU and SOMU4 points out that combining SOM with PCA or CCA can improve effectiveness and usefulness of SOM classifications in the PUB context, that is for predictions of streamflow indices in ungauged basins.

Results reported in Table 5 indicate that multiregression models based on SOMU4 outperform the other models for predicting MAR in ungauged basins. SOMU4 is as accurate as the optimal classification SOMY in predicting MAR in ungauged basins.

Table 5 illustrates a different picture for the prediction of the annual flood $\left(l_{1}\right)$. In this case the application of SOMPC3 results in the best NSE value, but, above all, performances of all alternative classifications are similar and low, definitely lower than SOMY and comparable with NOCLASS performances. This result was somehow expected, ours study adopts a very simplistic model (see Eq. 4) and the prediction of the central tendency of the flood frequency distribution (e.g., annual flood, median, index-flood, etc.) is indicated by the literature as one of the most critical steps required by the application of regional models to ungauged sites and is generally associated with a large uncertainty (see e.g., Brath et al., 2001; Castellarin, 2007; Kjeldsen and Jones, 2010). 
Table 5. Cross-validation of multiple regression models: NSE values for log-transformed streamflow indices ( $Q_{T}$ indicates the flood quantile with recurrence interval $T$, the highest NSE value among alternative classifications is highlighted in bold-italics).

\begin{tabular}{lccccccc}
\hline & Minimum & \multicolumn{7}{c}{ NSE } \\
\cline { 3 - 8 } & Record Length & NO-CLASS & SOMY & SOMX & SOMPC3 & SOMU4 & SOMU \\
\hline MAR & \multirow{2}{*}{ No limit } & 0.53 & 0.75 & 0.69 & 0.66 & $\mathbf{0 . 7 5}$ & 0.64 \\
$l_{1}$ & & 0.49 & 0.76 & 0.53 & $\mathbf{0 . 5 8}$ & 0.54 & 0.42 \\
\hline $\mathrm{Q}_{10}$ & \multirow{2}{*}{$30 \mathrm{yr}$} & 0.52 & 0.76 & 0.45 & 0.55 & 0.48 & $\mathbf{0 . 5 9}$ \\
$\mathrm{Q}_{50}$ & & 0.48 & 0.80 & 0.45 & 0.53 & 0.55 & $\mathbf{0 . 6 1}$ \\
\hline $\mathrm{Q}_{50}$ & \multirow{2}{*}{$40 \mathrm{yr}$} & 0.36 & 0.79 & 0.34 & $\mathbf{0 . 5 3}$ & 0.43 & 0.49 \\
$\mathrm{Q}_{100}$ & & 0.30 & 0.82 & 0.35 & 0.52 & 0.47 & $\mathbf{0 . 5 3}$ \\
\hline
\end{tabular}

Concerning the prediction of flood quantiles, the results of our study point out a clear supremacy of SOMU. Table 5 indicates that SOMU is associated with the highest NSE values 3 out of 4 times. It is interesting to note that also SOMPC 3 shows good performances, implying that the removal of redundant information involved in the identification of SOMX improves the accuracy of the regional models. Nevertheless, the lower bias and variability of residuals of SOMU relative to SOMPC3 is also evident in the boxplots of Fig. 9.

Concerning the box-plots of Fig. 9, a striking figure is the large number of outliers (circles) of relative residuals for the predictions of all streamflow indices considered in crossvalidation (outliers are defined as values situated at a distance from the lower and upper quartiles which is 1.5 times larger than the distance between the quartiles themselves). This may be due to the extreme simplicity of the linear regional model and the huge variability of climatic and hydrological characteristics of the consider catchments.

Furthermore, results obtained for SOMY (reference classification) and SOMX, SOMPC3, SOMU4 and SOMU reported in Table 5 and Fig. 9 also point out rather clearly that, aside from predictions of MAR, there is still a great margin for improvements. The gap in terms of performance between regional models based on SOMY and models based on all alternative classifications is significant. It is worth noting that this outcome has nothing to do with the limitations of the simplistic regional model adopted in the study (i.e., Eq. 4), nor the information used by the regional model. The structure of the regional model does not vary and the predictions in cross-validation of all regional model are based upon the same information (i.e., first three principal components of $X$ variables). Simply, SOMY transfers the streamflow information from gauged sites to ungauged ones in a more effective way. None of the catchment classifications based directly (SOMX) or indirectly (SOMPC3, SOMU, SOMU4), on the available catchment descriptors is as efficient as SOMY in transferring the streamflow information from gauged to ungauged sites. This gap may be reduced by identifying more informative catchment descriptors (see e.g., Savenije, 2010) given the growing availability of easily accessible high res- olution topographic and land-cover data, together with GIS tools for hydrologic analysis. Further improvements may probably stem from a process-based reorganization of the available information based on physically-based criteria that aims at further removing some noise characterizing the available set of catchment descriptors.

Concerning this point, future analyses could study the variability of catchment characteristics within each class (or node) of the SOM networks, testing whether this variability can be related with the uncertainty in the predicted streamflow indices. Moreover, future analyses, possibly focussing on larger datasets and diverse climatic and hydrological conditions, could further test the same classification algorithm (i.e., PCA/CCA and SOM) for catchment descriptors that combine (1) raw morphological information (e.g., catchment area, main channel and drainage network length, altimetry) to compute hydrologically significant characteristics, such as for instance the time of concentration or drainage density (Pallard et al., 2009), and (2) raw climatic information (e.g., catchment scale mean monthly and annual precipitation and temperature) to estimate aridity indices or net precipitation (Castellarin et al., 2007).

\section{Conclusions}

Our study analyses the effectiveness of unsupervised neural networks (Self Organising Maps, SOM) coupled with multivariate techniques for reducing the high dimensionality of catchment descriptors (i.e., Principal Component Analysis, PCA, and Canonical Correlation Analysis CCA) for producing catchment classifications on objective bases.

Catchment classification does not have a purpose in itself in the context of our analysis, and does not represent a mere scientific exercise, but represents the means to transfer information from gauged sites to ungauged ones, reducing the uncertainty of hydrological predictions in ungauged sites.

We consider some 300 Italian catchments scattered nationwide, which represent a complex compound featuring all Italian hydro-climatic settings, from Alpine to 

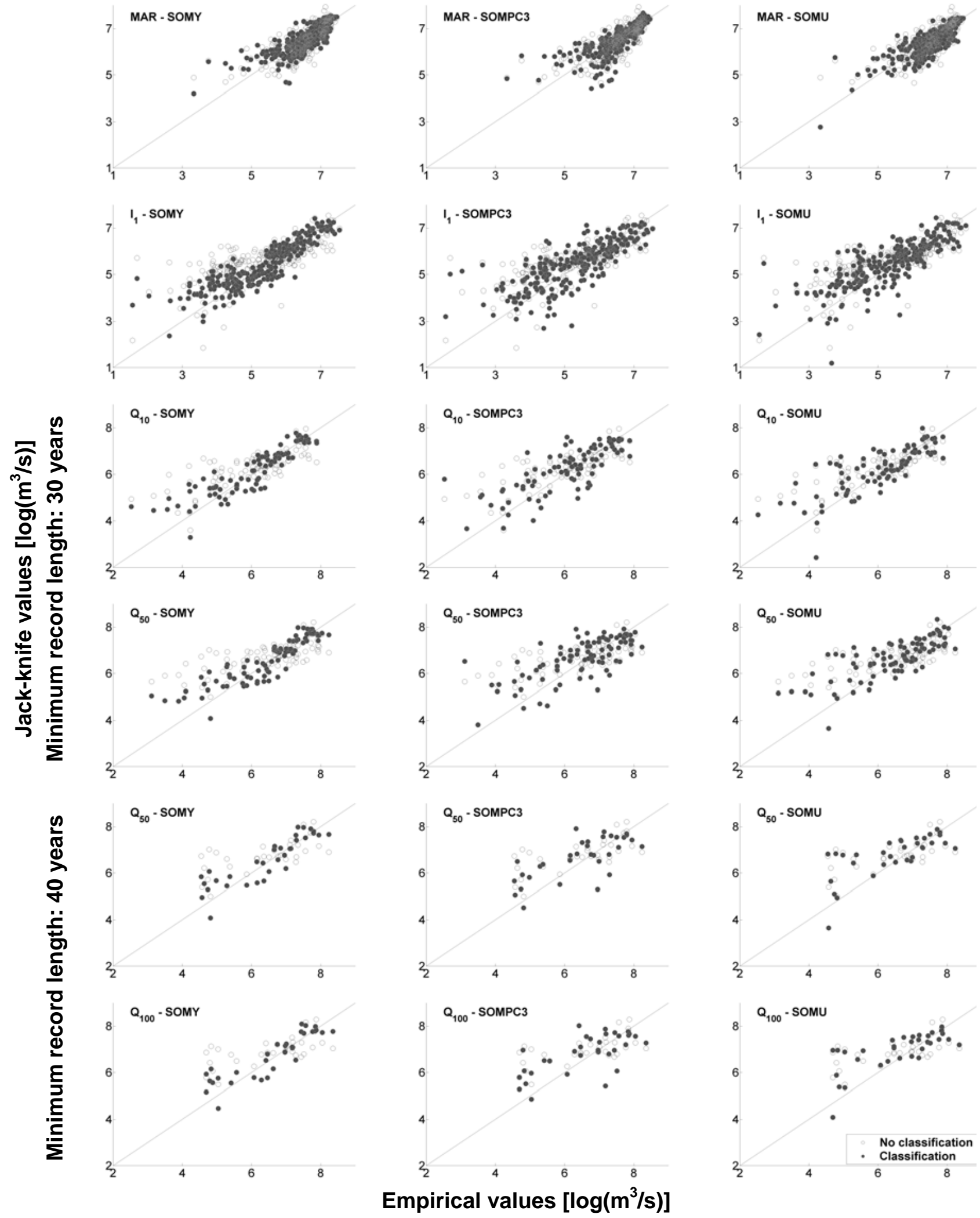

Fig. 8. Examples of scatter-plots (empirical vs. jack-knife values) obtained in cross-validation for some of the classifications considered in the study (the baseline classification NO-CLASS is reported in grey in each panel). 

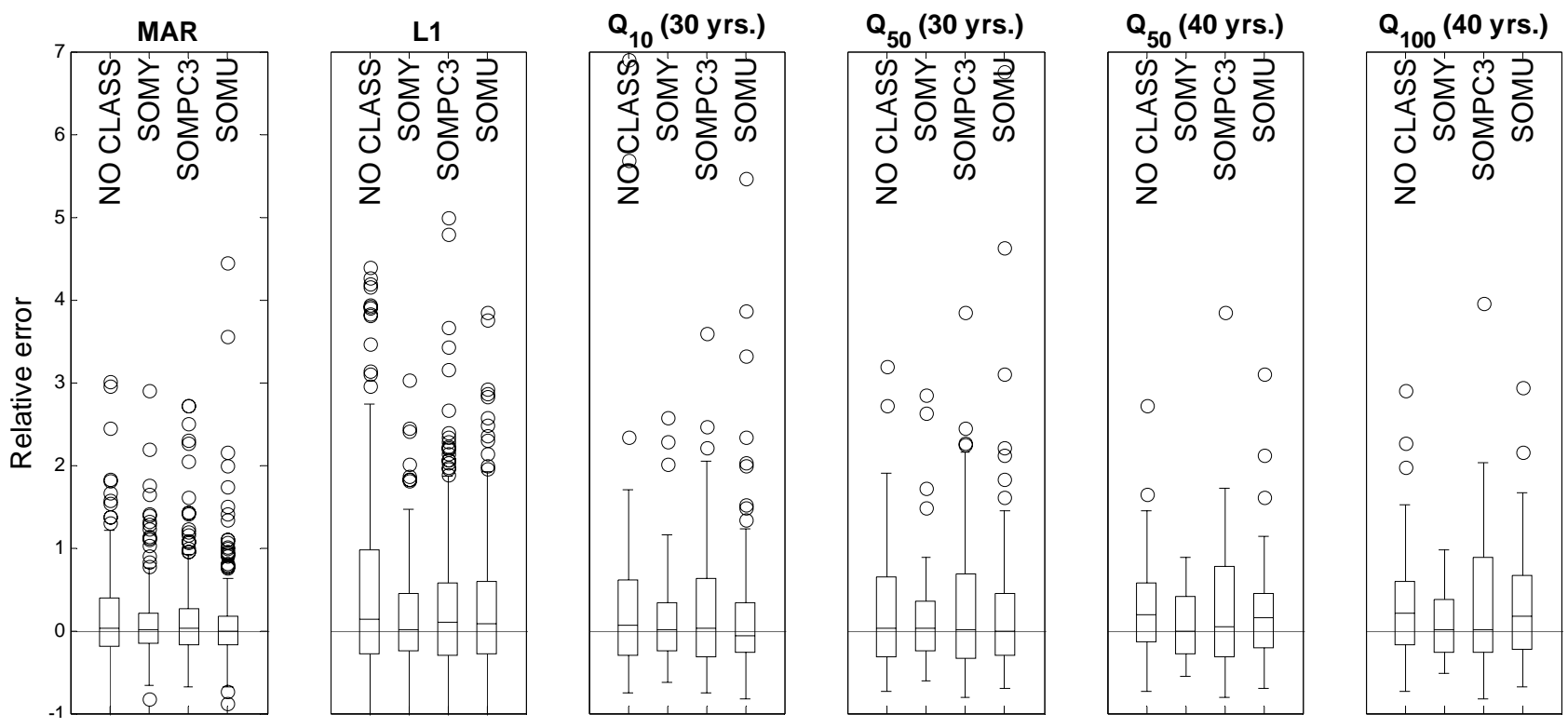

Fig. 9. Distribution of relative errors in terms of 25th, 50th and 75th percentiles, maximum and minimum values, and outliers (circles).

Mediterranean, from humid to semiarid, and from continental to maritime conditions.

The catchments are grouped into five different classifications, all delineated by means of unsupervised neural networks. One reference classification is identified by using as catchment descriptors indices of the streamflow regime and flood statistics (reference classification). Four alternative classifications are derived by referring to a number of geomorphologic and climatic catchment descriptors which can be computed for ungauged basins. One of this classification uses the entire set of descriptors as input variables to SOM, whereas the remaining three alternative classifications utilize as input variables a limited number of measures that are linear combinations of the original catchment descriptors obtained by applying PCA or CCA.

We compared the similarity of the alternative classifications with the reference classification. We also compared the accuracy of regional predictions of mean annual runoff, mean annual flood and flood quantiles for various recurrence intervals based on the alternative catchment classifications with the accuracy of the same predictions based on (1) the reference classification and (2) a baseline condition which groups together the entire system of Italian catchments (absence of classification). The regional predictions are obtained through the application of an extensive cross-validation procedure that simulates the ungauged conditions at each and every site.

Main outcomes of the study may be summarised as follows: (i) SOM's confirm their effectiveness and usefulness as objective criteria for pattern recognition and, in particular, for delineating catchment classifications; (ii) PCA and CCA can significantly improve the effectiveness and usefulness of SOM in the context of PUB, that is for reducing the uncertainty of hydrological predictions in ungauged sites; we strongly encourage to perform PCA, and in particular CCA, on the available set of catchment descriptors before applying SOM; (iii) catchment classification provides a great deal of information for enhancing hydrological predictions in ungauged basins, yet the application of objective but merely statistical criteria and algorithms (PCA and CCA with SOM) revealed some limitations that may be significantly reduced by switching from data-driven to data- and process-driven catchment classification. Designing a theoretical framework for combining these two different perspectives is an exciting open problem for future analyses. Our study focuses on a multipurpose catchment classification, future analyses will also consider hydrological classifications that are identified by focusing on a more specific water-problem, e.g., prediction of low-lows, flood flows, or surface water availability, to assess whether or not the same conclusions still hold.

Acknowledgements. The study has been partially supported by the Italian Government through its national grants to the programmes on "Advanced techniques for estimating the magnitude and forecasting extreme hydrological events, with uncertainty analysis" and "Relations between hydrological processes, climate, and physical attributes of the landscape at the regional and basin scales". Two anonymous reviewers and the handling editor, Peter Troch, are thankfully acknowledged for their very useful comments on a previous version of this paper.

Edited by: P. A. Troch 


\section{References}

Acreman, M. C. and Sinclair, C. D.: Classification of drainage basins according to their physical characteristics and application for flood frequency analysis in Scottland, J. Hydrol., 84(3), 365380, 1986.

Bai, Y., Wagener, T., and Reed, P.: A top-down framework for watershed model evaluation and selection under uncertainty, Environ. Modell. Softw., 24(8), 901-916, doi:10.1016/j.envsoft.2008.12.012, 2009.

Bárdossy, A.: Calibration of hydrological model parameters for ungauged catchments, Hydrol. Earth Syst. Sci., 11, 703-710, doi:10.5194/hess-11-703-2007, 2007.

Brath, A., Castellarin, A., Franchini, M., and Galeati, G.: Estimating the index flood using indirect methods, Hydrolog. Sci. J., 46(3), 399-418, 2001.

Brath, A., Castellarin, A., and Montanari, A.: Assessing the reliability of regional depth-duration-frequency equations for gaged and ungaged sites, Water Resour. Res., 39(12), 1367, doi:10.1029/2003WR002399, 2003.

Burn, D. H.: Cluster analysis as applied to regional flood frequency, J. Water Res. Pl., 115(6), 567-582, 1989.

Castellarin, A.: Application of probabilistic envelope curves for design-flood estimation at ungaged sites, Water Resour. Res., 43, W04406, doi:10.1029/2005WR004384, 2007.

Castellarin, A., Burn, D. H., and Brath, A.: Assessing the effectiveness of hydrological similarity measures for regional flood frequency analysis, J. Hydrol., 241(3-4), 270-285, 2001.

Castellarin, A., Galeati, G., Brandimarte, L., Brath, A., and Montanari, A.: Regional flow-duration curve: realiability for ungauged basins, Adv. Water Res., 27(10), 953-965, 2004.

Castiglioni, S., Lombardi, L., Toth, E., Castellarin, A., and Montanari, A.: Calibration of rainfall-runoff models in ungauged basins: a regional maximum likelihood approach, Adv. Water Resour., 33(10), 1235-1242, doi:10.1016/j.advwatres.2010.04.009, 2010.

Castiglioni, S., Castellarin, A., Montanari, A., Skøien, J. O., Laaha, G., and Blöschl, G.: Smooth regional estimation of low-flow indices: physiographical space based interpolation and top-kriging, Hydrol. Earth Syst. Sci., 15, 715-727, doi:10.5194/hess-15-7152011, 2011.

Céréghino, R. and Park, Y. S.: Review of the Self-Organizing Map (SOM) approach in water resources: Commentary, Environ. Modell. Softw., 24(8), 945-947, 2009.

Chokmani, K. and Ouarda, T. B. M. J.: Physiographical space-based kriging for regional flood frequency estimation at ungauged sites, Water Resour. Res., 40(12), W12514, doi:10.1029/2003WR002983, 2004.

Claps and the CUBIST Team: Development of an Information System of the Italian basins for the CUBIST project, Geophysical Research Abstracts, 10, 2008.

Dawson, C. W. and Wilby, R. L.: Hydrological modelling using artificial neural networks, Prog. Phys. Geog., 25(1), 80-108, 2001.

Dooge, J. C. I.: Looking for hydrologic laws, Water Resour. Res., 22(9), 46-58, 1986.

Efron, B.: The Jackknife the Bootstrap and Other Resampling Plans. Society for Industrial and Applied Mathematics, Philadelphia, Pennsylvania, 1982.

Gupta, H., Kling, H., Yilmaz, K. K., and Martinez, G. F.: Decomposition of the mean squared error and NSE performance criteria:
Implications for improving hydrological modelling, J. Hydrol., 377(1-2), 80-91, 2009.

Hall, M. J. and Minns, A. W.: The classification of hydrologically homogeneous regions, Hydrol. Sci. J., 44(6), 693-704, 1999.

Hosking, J. R. M.: L-moments: analysis and estimation of distributions using linear combinations of order statistics, J. Roy. Stat. Soc. B, 52, 105-124, 1990.

Hosking, J. R. M. and Wallis, J. R.: Regional Frequency Analysis, Cambridge: Cambridge University Press, 1997.

Hubert, L. and Arabie, P.: Comparing partitions, J. Classif., 2, 193218, 1985.

Hundecha, Y., Ouarda, T. B. M. J., and Bárdossy, A.: Regional estimation of parameters of a rainfall-runoff model at ungauged watersheds using the "spatial" structures of the parameters within a canonical physiographic-climatic space, Water Resour. Res., 44, W01427, doi:10.1029/2006WR005439, 2008.

ISPRA - DDS (Department for Soil Protection, former Geological Survey of Italy): The new Geological Map of Italy, 1:1 250000 scale, S.E.L.C.A. Florence, Italy, 2004.

Jingyi, Z. and Hall, M. J.: Regional flood frequency analysis for the Gan-Ming River basin in China, J. Hydrol., 296, 98-117, 2004.

Kaiser, H. F.: The application of electronic computers to factor analysis, Educ. Phychol. Meas., 20, 141-151, 1960.

Kalteh, A. M., Hjorth, P., and Berndtsson, R.: Review of the selforganizing map (SOM) approach in water resources: Analysis, modelling and application, Environ. Modell. Softw., 23, 835845, 2008.

Kjeldsen, T. R. and Jones, D. A: Predicting the index flood in ungauged UK catchments: On the link between data-transfer and spatial model error structure, J. Hydrol., 387(1-2), 1-9, 2010.

Kohonen, T.: Self-Organized formation of topologically correct feature maps, Biol. Cybern., 43, 59-69, 1982.

Kohonen, T.: Self-Organizing Maps, 2nd Edn., Springer, Berlin, ISBN 3-540-62017-6, 1997.

Kohonen, T.: Self-Organizing Maps, 3 Edn, Information Sciences, Springer, Berlin, Heidelberg, New York, 501 pp., 2001.

Krzanowski, W. J.: Principles of Multivariate Analysis, Oxford University Press, Oxford, 1988.

Ley, R., Casper, M. C., Hellebrand, H., and Merz, R.: Catchment classification by runoff behaviour with self-organizing maps (SOM), Hydrol. Earth Syst. Sci. Discuss., 8, 3047-3083, doi:10.5194/hessd-8-3047-2011, 2011.

McDonnell, J. J. and Woods, R. A.: On the need for catchment classification, J. Hydrol., 299, 2-3, 2004.

McDonnel, J. J., Sivapalan, M., Vache, K., Dunn, S., Grant, G., Haggerty, R., Hinz, C., Hooper, R., Kirchner, J., M. L., Selker, J., and Weiler, M.: Moving beyond heterogeneity and process complexity: A new vision for watershed hydrology, Water Resour. Res., 43(7), W07301, doi:10.1029/2006WR005467, 2007.

Maier, H. R. and Dandy, G. C.: Neural networks for the prediction and forecasting of water resources variables: a review of modelling issues and applications, Environ. Modell. Softw. 15, 101-123, 2000.

Maier, H. R., Jain, A., Dandy, G. C., and Sudheer, K. P.: Methods used for the development of neural networks for the prediction of water resources variables: Current status and future directions, Environm. Modell. Softw., 25, 891-909, 2010.

Nash, J. and Sutcliffe, J.: River flow forecasting through conceptual models, Part 1: a discussion of principles, J. Hydrol., 10, 282- 
$290,1970$.

Ouarda, T., Girard, C., Cavadias, G. S., and Bobée, B.: Regional flood frequency estimation with canonical correlation analysis, J. Hydrol., 254, 157-173, 2001.

Pallard, B., Castellarin, A., and Montanari, A.: A look at the links between drainage density and flood statistics, Hydrol. Earth Syst. Sci., 13, 1019-1029, doi:10.5194/hess-13-1019-2009, 2009.

Rand, W. M.: Objective criteria for the evaluation of clustering methods, J. Am. Stat. Assoc., 66(336), 846-850. doi:10.2307/2284239, 1971.

Robson, A. J. and Reed, D. W.: Statistical procedures for flood frequency estimation, in: Flood Estimation Handbook (FEH), Wallingford (UK), Vol. 3, Institute of Hydrology, 1999.

Savenije, H. H. G.: HESSOpinions "Topography driven conceptual modelling (FLEX-Topo)", Hydrol. Earth Syst. Sci., 14, 2681-2692, doi:10.5194/hess-14-2681-2010, 2010.

Shu, C. and Ouarda, T. B. M. J.: Flood frequency analysis at ungauged sites using artificial neural networks in canonical correlation analysis physiographic space, Water Resour. Res., 43, W07438, doi:10.1029/2006WR005142, 2007.

Sivapalan, M., Takeuchi, K., Franks, S. W., Gupta, V. K., Karambiri, H., Lakshmi, V., Liang, X., McDonnell, J. J., Mendiondo, E. M., OConnell, P. E., Oki, T., Pomeroy, J. W., Schertzer, D., Uhlenbrook, S., and Zehe, E.: IAHS Decade on Predictions in Ungauged Basins (PUB), 2003-2012: Shaping an exciting future for the hydrological sciences, Hydrolog. Sci. J., 48(6), 857-880, 2003.
Srinivas, V. V., Tripathi, S., Rao, A. R., and Govindaraju, R. S.: Regional flood frequency analysis by combining self-organizing feature map and fuzzy clustering, J. Hydrol., 348 (1-2), 148-166, 2008.

Stedinger, J. R., Vogel, R. M., and Foufoula-Georgiou, E.: Chp. 18 Frequency analysis of extreme events, in: Handbook of Hydrology, edited by: Maidment, D.R., New York (NY, USA), McGraw-Hill Inc, 1993.

Toth, E.: Classification of hydro-meteorological conditions and multiple artificial neural networks for streamflow forecasting, Hydrol. Earth Syst. Sci., 13, 1555-1566, doi:10.5194/hess-131555-2009, 2009.

Toth, E. and Castellarin, A.: Catchment classi?cation coupling Canonical Correlation Analysis and Self Organising Maps, Geophysical Research Abstracts, 10, EGU2008-A-12015, 2008.

Wagener, T., Sivapalan, M., Troch, P., and Woods, R.: Catchment Classification and Hydrologic Similarity, Geography Compass, 1/4, 901-931, doi:10.1111/j.1749-8198.2007.00039.x, 2007.

Yadav, M., Wagener, T., and Gupta, H.: Regionalization of constraints on expected watershed response behavior for improved predictions in ungauged basins, Adv. Water Res., 30(8), 17561774, doi:10.1016/j.advwatres.2007.01.005, 2007.

Yan, X., Chen, D., Chen, Y., and Hu, S.: SOM integrated with CCA for the feature map and classification of complex chemical patterns, Comput. Chem., 25(6), 597-605, 2001.

Zhang, Z. and Kroll, C. N.: The baseflow correlation method with multiple gauged sites, J. Hydrol., 347 (3-4), 371-380, doi:10.1016/j.jhydrol.2007.09.025, 2007. 